\title{
Empirical examples of using Big Internet Data for Macroeconomic Nowcasting
}

\author{
Kapetanios, George ${ }^{\text {a }}$ Marcellino, Massimiliano ${ }^{\text {b }}$ and Papailias, Fotis ${ }^{\text {a }}$ \\ a King's Business School, King's College London, ${ }^{\mathrm{b}}$ Bocconi University, Italy
}

\begin{abstract}
In this paper we present results for nowcasting and one-month-ahead forecasting three key macroeconomic variables: inflation (measured by the month on month growth rate in the Harmonized Index of Consumer Prices), retail sales (measured by the Retail Trade Index), and the Unemployment Rate. The exercise is conducted recursively in a pseudo out of sample framework, using monthly data for three economies: Germany, Italy and the $U K$. We assess the relative performance of Big Data (proxied via weekly Google Trends) and standard indicators (based on a large set of economic and financial variables). We also evaluate the role of several econometric methods and alternative specifications for each of them (with or without big data), for a total of 279 models and model combinations. In general, we find that Google Trends tend to slightly improve the forecasts of factor models and penalized regressions. Furthermore, a data-driven automated model selection strategy, where the forecasts from a set of best performing models over the recent past are pooled, performs particularly well, with Big Data present in about $65 \%$ of the pooled models (on average across the cases where the strategy is the best model).
\end{abstract}

Keywords: Big Data; Macroeconomic Nowcasting; Unstructured data 